\title{
Ekonomik Sipariş Miktarı Modellerinde Talebin Kısmen Ertelenmesi ve Bir Uygulama
}

\author{
Ahmed Adnan Hafedh ALGBURI* \\ Harun SULAK ${ }^{* * *}$
}

\begin{abstract}
$\ddot{O Z Z}$
Ekonomik Sipariş ve Üretim Miktarı modelleri stok kontrol modelleri içerisinde en yaygın kullanılanlarıdır. Basit ve kullanışlı olan bu modeller katı varsayımlar içerdiğinden gerçek hayatta ortaya çıkan problemlere cevap vermekte yetersiz kalmaktadır. Bu nedenle, bu modellerde yer alan varsayımlara ilave varsayımlar eklenmesi yahut mevcut varsayımların gevşetilmesi yoluyla yeni modeller geliştirilmektedir. Gelen siparişin defolu ürün içermemesi, ödemelerde gecikmeye ve stoksuzluğa (talebin ertelenmesine) izin verilmemesi bu modellerde yer alan temel katı varsayımlardandır. Bu varsayımlar esnetilerek gelişstirilen pek çok yeni model vardır. Bu çalışmada önceki çalışmalardan farklı olarak özellikle stoksuzluk durumunda talebin bir klsmının bir sonraki dönem karşılanmak üzere ertelenmesi durumunu defolu ürün ve ödemelerde belli bir süre gecikmeye izin verilmesi durumu ile birlikte ele alan bir ekonomik sipariş miktarı modeli önerilmektedir.

Çalışma üç bölümden oluşmaktadır. Birinci bölümde talebin kısmen ertelenmesi yani kısmi stoksuzluk durumu, gelen siparişin defolu ürün içermesi ve ödemelerde gecikmeye izin verilmesi durumu açıllanmakta ve bu alanda yapılan çalışmalar özetlenmektedir. İkinci bölümde karşılanamayan talebin kısmen ertelenmesi durumunu ele alan yeni bir ekonomik sipariş miktarı modeli önerilmektedir. Bu bölümde matematiksel modelin elde edilmesi, önceki çalışmaların önerilen modelin özel durumu olduklarının gösterilmesi ve modelle ilgili nümerik örnekler yer almaktadır. Üçüncü bölümde ise model parametrelerinin optimal değerler üzerindeki etkileri duyarlılık analizi ile incelenmektedir. Özellikle optimal sipariş miktarı ve toplam kârdaki değişimler ayrıntılı olarak ele alınmaktadır. Analiz sonuçlarına göre talebin erteleme oranının optimal sipariş miktarl ve toplam kâr üzerinde anlamlı bir etkisinin olmadığ görülmüştür. Diğer taraftan ödemelerde izin verilen gecikme süresi arttıkça ve defolu ürün oranı azaldıkça optimal sipariş miktarı azalmış, toplam kâr ise artmıştır.
\end{abstract}

Anahtar Kelimeler: Ekonomik sipariş miktarı, Ödemelerde gecikme, Defolu ürün, Stoksuzluk, Klsmi erteleme

JEL Sinıflandirması: C02, C61, M11

\section{Partial Backordering in Economic Order Quantity Models and an Application}

\begin{abstract}
Economic Order and Production Quantity models are the most used stock control models. These simple and useful models are inadequate to respond to the real-life problems as they contain rigid assumptions. Therefore, new models are developed by adding additional assumptions to the assumptions in these models or by loosening existing assumptions. Among the rigid assumptions contained in these models are incoming order does not contain any defective items,
\end{abstract}

Bu çalışma Ahmed Adnan Hafedh Algburı tarafından hazırlanan doktora tezinden türetilmiştir.

* Doktora Öğrencisi, Süleyman Demirel Üniversitesi, Sosyal Bilimler Enstitüsü, dr_ahmedovj@yahoo.com

** Prof. Dr., Süleyman Demirel Üniversitesi, İ̈BF İşletme Bölümü, aeroglu@sdu.edu.tr

*** Dr. Öğr. Üyesi, Süleyman Demirel Üniversitesi, IIIBF Ekonometri Bölümü, harunsulak@sdu.edu.tr

(Makale Gönderim Tarihi: 06.01.2019/ Yayına Kabul Tarihi: 15.03.2019

Doi Number: 10.18657/yonveek.508931 
delay in payments and backordering (shortages) of the demand are not allowed. Many new models have been developed by loosening these assumptions. In this study, unlike the previous studies, an economic order quantity model is proposed which deals with the fact partial backordering of the demand postponed to meet in the next period, defective items and permissible delay in payments.

The study consists of three parts. In the first part, partial shortage and backordering of the demand, the defective item in the incoming order and the permissible delay in payments are explained and the studies in this area are summarized. In the second chapter, a new model of economic order quantity is proposed, which allows partial shortage and backordering of the demand. In this section, obtaining the mathematical model, previous studies are the special case of the proposed model and numerical examples related to the model are given. In the third chapter, the effects of the model parameters on the optimal values are examined by sensitivity analysis. Especially changes of optimal order quantity and total profit are discussed in detail. According to the results of the analysis, it was observed that the backordering rate of demand did not have a significant effect on optimal order quantity and total profit. On the other hand, as the permissible delay time in payments increased and the rate of defective products decreased, the optimal order quantity decreased and the total profit increased.

Keywords: Economic Order Quantity, Permissible Delay in Payments, Defective Items, Shortages, Partial Backordering

JEL Classification: C02, C61, M11

\section{GíRIŞ}

Stok veya envanter, bir işletmenin üretimi gerçekleştirmek veya müşterilerin isteğine cevap verebilmek amaciyla kullandığı ve elinde bulundurduğu madde ve malzemelerdir. Her işletme kendi amaçları ve faaliyet alanı doğrultusunda farklı türde stok bulundurmaktadır. Stok yönetiminde esas, elde stok bulundurmanın ile stok bulundurmama sonucu ortaya çıkacak maliyetlerinin dengelenmesidir. Bunun için iyi bir stok politikası ile elde bulundurulacak stok miktarı ve hangi sıklıkla sipariş veya üretim yapılacağına karar verilmektedir.

Bütün stok kontrol problemlerinde amaç toplam maliyeti minimum veya toplam kârı maksimum yapacak sipariş ve üretim miktarının ve bu sipariş ve üretimin ne zaman başlayıp biteceğinin belirlenmesidir. Bunların belirlenebilmesi için çok basit pek çok yöntem yanında karmaşık problemlerin çözümü için kullanılacak oldukça fazla matematiksel model geliştirilmiş̧ir. Ekonomik Sipariş ve Ekonomik Üretim Miktarı modelleri stok kontrol modelleri içerisinde en çok kullanılan iki modeldir. Basit ve kullanışlı olan bu modeller içerdikleri katı varsayımlar nedeniyle gerçek hayatta ortaya çıan problemlere cevap verememektedir. $\mathrm{Bu}$ modellerde yer alan katı varsayımlara ilave varsayımlar eklenmesi yahut mevcut varsayımların gevşetilmesi yoluyla yeni modeller geliştirilmiştir. Gelen siparişin veya üretimin defolu ürün içermesi, ödemelerde gecikmeye izin verilmesi, öğrenme, enflasyon ve paranın zaman değeri etkilerinin analizi, stoksuzluğa ve talebin ertelenmesine izin verilmesi ve ürünlerde bozulma gibi yeni açılımlar olarak ele alınan faklı durumların analiz edildiği pek çok model literatürde yerini almıştır.

$\mathrm{Bu}$ çalışmada, çevrim süresi içinde karşılanamayan talebin kısmen veya tamamen sonradan karşılanması için stoksuzluğa ve sipariş tutarının ödenmesinde belli bir süre gecikmeye izin verilmesi ile defolu ürün olmas1 durumunu ele alan yeni bir model geliştirilmektedir. Geliştirilen modelin için hipotetik değerler 
kullanılarak örnekler verilmekte ve model parametrelerindeki değişimin optimal değerleri nasıl etkilediği duyarlılık analizi ile araştırılmaktadır.

Çalışma üç ana bölümden oluşmaktadır. Birinci bölümde çevrim süresi içerisinde karşılanamayan talebin belli bir oranının ertelenmesi, gelen sipariş içerisinde defolu ürün olması durumu ve ödemelerde belli bir süreye kadar gecikmeye izin verilmesi konuları ele alınmaktadır. Ayrıca bu bölümde kısmi erteleme, defolu ürün ve ödemelerde gecikme durumunu ele alan literatürdeki önceki çalışmalar özetlenmektedir. İkinci bölümde önerilen modelin matematiksel formülasyonu elde edilmektedir. Ödemelerde izin verilen gecikme süresinin kısa ve uzun oluşuna göre iki farklı durumu için optimal değerlerin elde edilmesi, önceki modellerden üç tanesinin bu çalışmada önerilen modelin özel durumu olduklarının gösterilmesi, hipotetik örneklerle modelin geçerliliğin gösterilmesi de ikinci bölümde ele alınan konulardır. Üçüncü bölümde model analizinde en önemli bölüm olan duyarlılık analizi yapılmaktadır. Duyarlılık analizi ile model parametrelerindeki değişimin optimal değerleri ne yönde ve hangi şiddette etkilediği özellikle optimal sipariş miktarı ve toplam kâr özelinde değerlendirilmektedir.

\section{GECIKKME}

I. KISMİ ERTELEME, DEFOLU ÜRÜN ve ÖDEMELERDE

Ekonomik Sipariş ve Üretim Miktarı modelleri yaklaşık bir asırdır kullanılmaktadır. Bu modellerde gerçek hayatı tam temsil etmeyen varsayımlar bulunmaktadır. Gelen siparişin tamamının kusursuz ürünlerden oluşması, ödemelerin malın tesliminde peşin yapılması ve stoksuzluk durumunda talebin ertelenmesi gibi bir esnekliğin olmaması bu çalışmada ele alınacak ve gevşetilecek varsayımlardandır. Defolu ürün olması, ödemelerde gecikmeye ve stoksuzluğa (talebin ertelenmesine) izin verilmesi bu katı varsayımların gevşetilmesi sonucu modellere dâhil edilen yeni açılımlardır. Çalışmanın bu kısmında stoksuzluğa izin verilmesi durumunda çevrim süresi içerisinde karşılanamayan talebin bir kısmının bir sonraki çevrim süresinden karşılanmak üzere ertelenmesi, ödemelerde gecikmeye izin verilmesi ve defolu ürün durumu açıklanacak ve bu açılımları modelleyen literatürdeki çalışmalar incelenecektir.

\section{A. Kısmi Erteleme}

Stoksuzluğa izin verilmesi ve müşterilerin siparişlerinin bir kısmını bir sonraki siparişten karşılanmak üzere ertelemesi diğer kısmı için başka bir satıcıya gitmeleri durumu kısmi erteleme olarak tanımlanmaktadır. $\mathrm{Bu}$ durumda karşılanamayan talebin bir kısmı satış kaybı olarak karşımıza çıkmaktadır. (Sulak, 2008) Gerçek hayatta çok görülen talebin kısmen ertelenmesi konusunda oldukça fazla çalışma yapılmışıtır.

Stoksuzluk durumunda talebin kismen ertelenmesi konusunu ele alan çalışmaların öncülügünü Hadley ve Whitin (1963) ile Montgomery vd. (1973) yapmışlardır. Rosenberg (1979) ve Park (1982) ise, Hadley \& Whitin (1963) ile Montgomery vd. (1973) temel çalışmasını geliştirmişlerdir. 
Wee (1989) önce Hessian matrisini kullanarak kısmi erteleme durumunda maliyet optimizasyonunu çözümlemiş, sonraki çalışması Wee (1993) ile de bozulan stoklar için kısmi erteleme modeli geliştirmiştir.

Zeng (2001) poisson talep fonksiyonu ve üstel üretim zamanı için kısmi erteleme modelini çalışmıştır. Abad (2001), öncelikle Hadley \& Whitin (1963) ile Montgomery vd. (1973) temel çalışmasını geliştirmiş, sonrasındaki çalışması ile de Abad (2003) sonsuz üretim için bozulan stoklara yönelik kısmi erteleme modeli türetmiştir. Abad (2008) yılındaki çalışması ile bozulan stoklara yönelik k1smi erteleme modelini geliştirmiştir.

Papachristos \& Skouri (2000) ise ilk olarak sürekli envanter sisteminde sonsuz planlama dönemi için zamana bağlı deterministik değişen talep durumunda kısmi erteleme modelini geliştirmişler, sonraki çalışmalarında Papachristos \& Skouri (2003) ise Wee (1999) yaptığı çalışmanın genelleştirilmesini ele almışlardır.

Padmanabhan \& Vrat (1995) çalışmalarında müşterilerin sabırsızlık fonksiyonunun bekleme zamanına bağlı olduğu yaklaşımı ile stoksuzluk döngüsü ve kısmi erteleme modeli geliştirmiştir. Dye \& Ouyang (2005), Padmanabhan \& Vrat (1995)' 'n çözümünü geliştirerek bozulabilen stoklar için süre oranlı kısmi erteleme oranı kullanmışlardır.

Giri vd. (2005) artan talep oranı ve uyarlanabilir üretim oranı parametreleri çerçevesinde kısmi erteleme modelini çalışmışlardır. Sphicas (2006) araştırmasında sabit ve lineer erteleme maliyetleri ile ekonomik sipariş miktarını ve ekonomik üretim miktarını incelemiştir.

San-José vd. (2007) çalışmalarında sürekli envanter modeli, sabit ve bilinen talep miktarı çerçevesinde, sonraki çalışmalarında da San-José vd. (2008) kısmi ertelemenin üstel bir fonksiyon olduğu varsayımı çerçevesinde kısmi erteleme için optimal ekonomik sipariş miktarını araştırmışlardır. San-José vd. (2009) çalışmaları ile birim stoksuzluk maliyetinin kısmi ertelemenin tedariki için gereken süreyi azaltan bir fonksiyon olarak tanımlayarak kısmi erteleme için ekonomik sipariş miktarı modeli çerçevesi oluşturmuşlardır.

Pentico \& Drake (2009) deterministik klasik ekonomik sipariş miktarı modeline dayalı kısmi erteleme için ekonomik sipariş miktarı için, Pentico vd. (2009) ise ekonomik üretim miktarı için formül türetmişlerdir.

Omar vd. (2010), optimal ekonomik sipariş miktarı ve ekonomik üretim miktarı sorununa alternatif bir çözüm olarak tam kareye tamamlama yöntemini uygulamışlardır.

Sana (2010) ise fiyat bağımlı talebi olan ve zamana bağlı bozulan ürün için sonsuz planlama döneminde kısmi erteleme durumu için ekonomik sipariş miktarı modelini çalışmıştır.

Yang vd. (2010), Hadley ve Whitin (1963) ile Montgomery vd. (1973) temel çalışmasını geliştirerek bozulan stoklar için talebin stok miktarına bağlı ve enflasyon ortamında kısmi erteleme modelini çalışmışlardır.

Roy vd. (2011) gelen siparişin tekdüze dağllıma uyan belli bir oranda defolu ürün içerdiği ve kısmi erteleme durumunu ele almışlardır. Çalışmalarında 
stoksuzluk durumunda talebin kısmen ertelenmesi diğer kısmının ise satış kaybı olması ele alınarak yeni bir ekonomik sipariş miktarı modeli geliştirmişlerdir.

Taleizadeh vd. (2012), çalışmalarında kısmi erteleme ve tam erteleme için dışbükey maliyet fonksiyonu minimizasyonu yöntemi ile ekonomik sipariş miktarı modeli önermişlerdir.

Sarkar \& Sarkar (2013), bozulabilen ve stok miktarına bağlı talebi olan ürünler için zamana bağlı kısmi erteleme ve zaman bağlı bozulma varsayımları altında toplam stok maliyetini mininize edecek optimal dönem uzunluğunu belirlemişlerdir.

Wee vd. (2014) ise sabit ve lineer kısmi erteleme maliyetleri varsayımı ile ekonomik üretim miktarı modeli geliştirmişlerdir.

Taleizadeh vd. (2013), satın alma maliyetinin belirli bir kısmının dönem başında ödendiği varsayımı ile kısmi erteleme için ekonomik sipariş miktarı modeli geliştirmişlerdir.

Khalilpourazari vd. (2016)çalışmalarında depoda kullanılmayan alanlardan kaynaklanan maliyeti de dikkate alarak kısmi erteleme için ekonomik sipariş miktarı modeli geliştirmiş̧lerdir.

Taleizadeh vd. (2016) ise defolu ürünlerin yeniden işlenmesi sürecini analize dâhil ederek kısmi erteleme için ekonomik sipariş miktarı modeli oluşturmuşlardır.

\section{B. Defolu Ürün Durumu}

Klasik ekonomik sipariş miktarı modelinin gerçekçi olmayan bir diğer varsayımı üretilen veya tedarikçilerden temin edilen ürünlerin hatasız ve sağlam olduğu diğer bir ifade ile kusursuz ürünler olmasıdır. Gerçek hayatta ise sipariş verilen veya üretilen ürünlerin bir bölümünün defolu ve hatalı olması kaçınılmaz bir durumdur. Üretim sürecinde belirli bir süre normal şekilde kusursuz ve hatasız üretim yapılırken makine ve teçhizatta yaşanan arızalar neticesinde bir süreden sonra defolu ve hatalı ürünlerin üretilmesi söz konusu olmaktadır. $\mathrm{Bu}$ defolu ürünler yeniden işlenerek ya da tamir edilerek normal şekilde kusursuz ürüne dönüştürülebileceği gibi defolu ürün şeklinde düşük fiyat üzerinden satılabilmekte veya tamamen işe yaramaz olanlar hurdaya ayrılabilmektedir. (Sulak, 2008)

Defolu ürün durumu ile ilgili olarak özellikle son yirmi yılda oldukça fazla çalışma yapılmıştır. İlk olarak Rosenblatt \& Lee (1986) üretimde belirli oranda defolu ürün üretilmesi varsayımı ile ekonomik üretim miktarı modelini geliştirmişlerdir. Salameh \& Jaber (2000) sipariş sonucu gelen ürünlerdeki defolu oran yüzdesinin rassal olarak tekdüze dağılıma uyduğu, gelen ürünlerin tamamının muayene sürecinden geçtiği ve defolu olduğu belirlenen ürünlerin iskontolu fiyat üzerinden satıldığı varsayımı altında ekonomik sipariş miktarı modelini geliştirmişlerdir. Geliştirdikleri modelde stoksuzluğa izin verilmemektedir. Salameh \& Jaber (2000)'in ortaya koyduğu deterministik stok kontrol modeli, ekonomik sipariş miktarı literatüründe defolu ürün konusunu ele alan ilk çalışma olmuştur.

Salameh \& Jaber (2000) modelinin oluşturulmasındaki yanlışlıklar önce Cárdenas-Barrón (2000) sonra da Maddah \& Jaber (2008) çalışmaları ile 
düzeltilmiştir. Goyal \& Cárdenas-Barrón (2002) ise Salameh \& Jaber (2000) modelini ele almışlar ve optimal sipariş miktarını bulacak daha kolay bir yöntem geliştirmişlerdir.

Eroğlu vd. (2004) defolu ürünlerin yeniden işlenmesi yerine iskontolu olarak satılmasının daha uygun olduğu yaklaşımını üretim miktarı modellerinde ele almışlar ve yeni bir model geliştirmişlerdir. Bu modelde defolu ürün oranının dağılımı tekdüze olup üretim sürecinin sona ermesiyle defolu ürünler indirimli fiyattan satılmakta ayrıca stoksuzluğa da izin verilmektedir.

Papachristos \& Konstantaras (2006), Salameh \& Jaber (2000) temel modelindeki stoksuzluk durumuna girmemeyi sağlayacak şartları iyileştirerek modeli geliştirmişlerdir.

Wee vd. (2007), Salameh \& Jaber (2000) temel modeline defolu ürün olması durumunda tam erteleme ile satış kaybının yaşanmayacağı durumunu ele alan bir model geliştirmiş̧ir. Fakat Wee vd. (2007) modelinde çevrim süresi içerisinde karşılanamayan talebin gelen siparişle tamamının hemen karşılandığ varsayılmıştır.

Eroglu \& Ozdemir (2007) ise Salameh \& Jaber (2000) modelini geliştiren Wee vd. (2007) modelindeki ertelenen talebin siparişin gelmesiyle defolu ürünler ayrılmadan karşılanması şeklindeki mantık hatasını gidererek, bir önceki dönemde karş1lanamamış olan talebin yeni gelen siparişlerin muayene edilip defolu ürünlerin ayrılmasından sonra kalan sağlam ürünlerden karşılandığı varsayımını ekleyerek daha doğru bir ekonomik sipariş miktarı modeli geliştirmişlerdir.

Sulak (2008), Eroglu \& Ozdemir (2007) modeline katkıda bulunmuş ve alıcılara satıcılar tarafından izin verilen ödemelerde belli bir süre gecikme durumunu modele dahil ederek genel bir model elde etmiştir.

Jaber vd. (2014) defolu ürünlerin yeniden işlenebileceği veya ikincil piyasada satılabileceği varsayımları ile Salameh \& Jaber (2000) temel modelini geliştirmiş ve yeni bir model önermişlerdir.

Sharifi vd. (2015) muayene hatalarının ve kısmi ertelemenin ekonomik sipariş miktarı üzerinde etkisini inceleyerek optimal sipariş miktarı ve kısmi erteleme seviyesini belirlemişlerdir.

Sarkar \& Saren (2016) defolu ürün, muayene hataları ve garanti maliyetlerini dikkate alarak bir ekonomik sipariş miktarı modeli geliştirmişlerdir. Çalışmanın sonuçlarına göre ürünlerin tamamının muayene edilmesi toplam stok maliyetlerini arttırmaktadır.

\section{C. Ödemelerde Gecikmeye İzin Verilmesi}

Ekonomik sipariş miktarı modellerinde sipariş tutarının malın teslimatında peşin olarak yapıldığ 1 varsayılmaktadır. Ancak uygulamada mal teslimi ile ödemenin yapılması arasında ödemelerin yapılması için tedarikçi tarafından izin verilen bir süre vardır. Bu süre zarfında sipariş tutarı için herhangi bir ceza söz konusu olmamakta fakat bu sürenin aşımı sonrasında önceden tarafların üzerinde anlaştığı bir faiz oranı işletilmektedir. Niteliği itibariyle bu uygulama tedarikçilerin müşterilerine bir nevi kredi uygulamasıdır. Müşteri, 
tedarikçi tarafından izin verilen ödeme süresinden önce stoklarını satarak nakde dönüştürme ve bu nakdi tedarikçi tarafından tanınan vade tarihinin sonuna kadar kullanmak suretiyle ekonomik fayda elde etme imkânına sahiptir. (Aggarwal \& Jaggi, 1995)

Goyal (1985) tarafindan oluşturulan model, ödemelerde gecikmeye izin verilmesi hususundaki ilk stok modellerindendir. Modelde ödemelerde gecikmeye izin verilmesi durumunda ekonomik sipariş miktarının marjinal olarak arttı̆̆ ve yıllık maliyetlerin önemli ölçüde azaldığı görülmüştür. Ödemelerde gecikmeye izin verilmesi suretiyle maliyetlerden sağlanan tasarruf genel itibariyle faizsiz olarak ödemelerin geciktirilmesi nedeniyle elde edilen avantajlardan kaynaklanmaktadır. Ödemelerde gecikmeye izin verilmesi durumunda sipariş miktarı artmakta ve buna bağlı olarak sipariş sayısı azalmaktadır.

Aggarwal \& Jaggi (1995), Goyal (1985) tarafindan oluşturulan bu modele bozulan ürün kısıtını eklemiş ve model analizinde izin verilen gecikme süresi uzadıkça sipariş miktarında marjinal bir artma ve toplam maliyetlerde önemli düzeyde bir azalma söz konusudur. Öte yandan bozulma oranı arttıkça ödemelerde gecikmeye izin verilmesi nedeniyle sağlanan maliyetlerden tasarruf miktarı azalmaktadır.

Jamal vd. (1997) Aggarwal \& Jaggi (1995) modelinde ele alınmayan stoksuzluk durumunu modele ekleyerek yeni bir model geliştirmişlerdir.

Hwang \& Shinn (1997), talebin bağımlı olduğu durum, ürünlerde bozulma ve ödemelerde gecikme konusunu ele almışlardır. Çalışmalarında talep oranı satı̧ fiyatının fonksiyonu olup bozulma oranı ise üssel dağılıma uymaktadır.

Chung (1998), Goyal (1985) modelindeki sonuçları daha kısa sürede elde edecek bir teknik geliştirmiş ve basit ve kullanışlı bir teorem ortaya koymuştur.

Jamal vd. (2000) Jamal vd. (1997) çalışmasını geliştirerek alıcının toplam maliyetini minimum yapacak ödeme planını elde etmişlerdir.

Chung \& Huang (2006) defolu ürün olması durumu ile ödemelerde belli bir süre gecikmeye izin verilmesi durumunu ele alan yeni bir ekonomik sipariş miktarı modeli elde etmişlerdir. Chung \& Huang (2006) modeli ödemelerde gecikme konusunu ilk ele alan Goyal (1985) modeli ile defolu ürün durumunu ilk defa çalışan Salameh \& Jaber (2000) modelinin birleştirilmiş ve genelleştirilmiş halidir.

Sulak (2008) ise Eroglu \& Ozdemir (2007) ile Chung \& Huang (2006) modellerini birleştirerek ödemelerde gecikme, defolu ürün ve stoksuzluk durumunu üçünü beraber analiz edecek yeni bir model geliştirmiştir.

Ödemelerde gecikmeye izin verilmesi durumunu ele alan diğer çalışmalarla ilgili Sulak \& Eroğlu (2009) kapsamlı bir yazın taraması sunmuşlardır.

Buraya kadar ele alınan çalışmalar içerisinde stoksuzluk durumunda talebin kısmen veya tamamen ertelenmesi, defolu ürün durumu ve ödemelerde gecikmeye izin verilmesi durumunu ele alan temel çalışmalar ile önerilen model aşağıdaki tabloda özetlenmiştir. 
Tablo 1. Yapılan temel çalıșmalar

\begin{tabular}{|l|c|c|c|c|}
\hline $\begin{array}{c}\text { Yapılan Çalışma [Yazar } \\
\text { (yıl)] }\end{array}$ & Tam erteleme & Kısmi erteleme & Defolu ürün & Ödemlerde gecikme \\
\hline Salameh \& Jaber (2000) & & & $\checkmark$ & \\
\hline Chung \& Huang (2006) & $\checkmark$ & & & $\checkmark$ \\
\hline Eroglu \& Ozdemir (2007) & $\checkmark$ & & $\checkmark$ & $\checkmark$ \\
\hline Sulak (2008) & $\checkmark$ & & $\checkmark$ & $\checkmark$ \\
\hline Taleizadeh vd. (2013) & & $\checkmark$ & $\checkmark$ & $\checkmark$ \\
\hline Taleizadeh vd. (2016) & & $\checkmark$ & $\checkmark$ & \\
\hline Önerilen model & & $\checkmark$ & & \\
\hline
\end{tabular}

Tablodan da görüldüğg̈ gibi bu çalışmada geliştirilen model Sulak (2008) tarafından geliştirilen modelin kısmi erteleme durumunu içerecek şekilde geliştirilmiş ve genelleştirilmiş bir versiyonudur. Bu yönüyle bu çalışma önceki çalışmalardan ayrılmaktadır.

\section{MODEL ÖNERISİ}

$\mathrm{Bu}$ çalışmada çevrim süresi içerisinde karşılanamayan talebin bir kısmının ertelendiği aynı zamanda gelen siparişlerin belli bir oranda defolu ürün içerdiği ve sipariş tutarının ödenmesinde alıcıya belli bir süreye kadar gecikmeye izin verildiği genel bir model önerilmektedir. Elde edilen model sayısal örneklerle test edilmektedir. Talebin kısmi erteleme oranı, ödemelerde izin verilen gecikme süresi ve defolu ürün oranındaki değişimlerin optimal değerler üzerindeki etkileri duyarlılık analizi ile araştırılmaktadır. Çalışmanın bu kısmında matematiksel modelin elde edilmesinde kullanılan simgeler ve varsayımlar verilecek ve optimal değerleri veren formüller çıkarılacaktır. Ayrıca sayısal örnekler ve önceki çalışmaların burada önerilen modelin özel durumu olduğu gösterilecektir.

\section{A. Modelde Kullanılan Simgeler ve Varsayımlar}

Modelde kullanılan simgeler aşağıdaki gibidir:

y sipariş miktarı

w stoksuzluk miktarı

D ylllk talep

$p \quad$ defolu ürün oranı

$\mathrm{f}(\mathrm{p}) \quad$ defolu ürün oranının olasılık yoğunluk fonksiyonu

$\mathrm{K}$ sipariş maliyeti

c birim satın alma maliyeti

$s \quad$ birim satış fiyatı (kusursuz ürün)

$v \quad$ birim satış fiyatı (defolu ürün)

$h \quad$ birim stok bulundurma maliyeti

$\pi \quad$ birim stok bulundurmama maliyeti

$x \quad$ birim zamanda inceleme oran

$d \quad$ birim inceleme maliyeti

$\mathrm{T}$ çevrim süresi

M ödemeler için verilen gecikme süresi

$t \quad$ gelen siparişin incelenme süresi

$\mathrm{t}_{1} \quad$ çevrim süresi içerisinde karşılanamayan talebin gelen yeni siparişin incelenip defolu ürünler belirlenip ayrıldıkça geriye kalan sağlam ürünlerden karşılandığı süre 
$\mathrm{t}_{2}$ bir önceki dönem karşılanamayan talebin belli bir oranda karşılanmasından sonra incelenmesi işleminin bitmesine kadar geçen süre, $\mathrm{t}-\mathrm{t}_{1}$

$t_{3} \quad$ inceleme süresi bittikten sonra çevrim süresi içerisinde talebin karşılandığı süre

$\mathrm{t}_{4} \quad$ talebin kısmen ertelendiği sure

F bir çevrim süresi içinde talebin stoksuzluğa düşmeden karşılanabildiği süre

$\mathrm{I}_{\mathrm{e}} \quad$ izin verilen gecikme süresinde satış gelirlerinin değerlendirildiğ $\mathrm{i}$ yıllık faiz oranı

$\mathrm{I}_{\mathrm{o}} \quad$ gecikme süresi bitiminde ödenmeyen sipariş tutarı için gecikme cezası olan yıllık faiz oranı

$\mathrm{y}^{*} \quad$ optimal ekonomik sipariş miktarı

$\mathrm{w}^{*} \quad$ maksimum stoksuzluk miktarı

$\mathrm{T}^{*} \quad$ optimal çevrim süresi (yıl)

$\mu \quad$ talebin kısmi erteleme (stoksuzluk) oranı

$\mathrm{E}($.$) beklenen değer$

Önerilen model için aşağıdaki varsayımlar yapılmıştır:

- Talep ve tedarik süresi sabit ve bilinmektedir.

- Gelen siparişler tekdüze dağılıma uyan bir oranda defolu ürün içermektedir.

- Gelen siparişteki defolu ürünler incelenerek tespit edilmekte ve indirimli fiyattan tek parti halinde satılmaktadir.

- Karşılanamayan talep için kısmi ertelemeye, stoksuzluğa izin verilmektedir.

- Ödemelerde belli bir süre gecikmeye izin verilmektedir. İzin verilen gecikme süresi içerisinde satılan ürünlerden elde edilen geliri piyasa faiz oranında değerlendirilmekte ve buradan faiz geliri elde edilmektedir. Gecikme süresi bitiminde, toplam sipariş tutarı için ödeme yapılmakta ödenmeyen tutar için belli bir faiz oranında gecikme cezası uygulanmaktadır.

\section{B. Matematiksel Model}

Modelin işleyişi Şekil 1'de verilmiştir. Buna göre; çevrim süresi T olup çevrim süresi başında gelen sipariş miktarı, $y^{\prime}$ dir. Bu siparişin rassal olarak $p$ oranında defolu ürün içerdiği bilinmektedir. Gelen siparişlerin tamamı belli bir $t$ süresinde incelenip defolu ürünler tespit edilmekte ve ayrılmaktadır. Ayrılan bu ürünlerin toplamı py kadar olup inceleme süresi olan $t$ süresi bitiminde indirimli fiyattan tek parti olarak satılmaktadır. 
Şekil 1. Önerilen Modelin İşleyişi

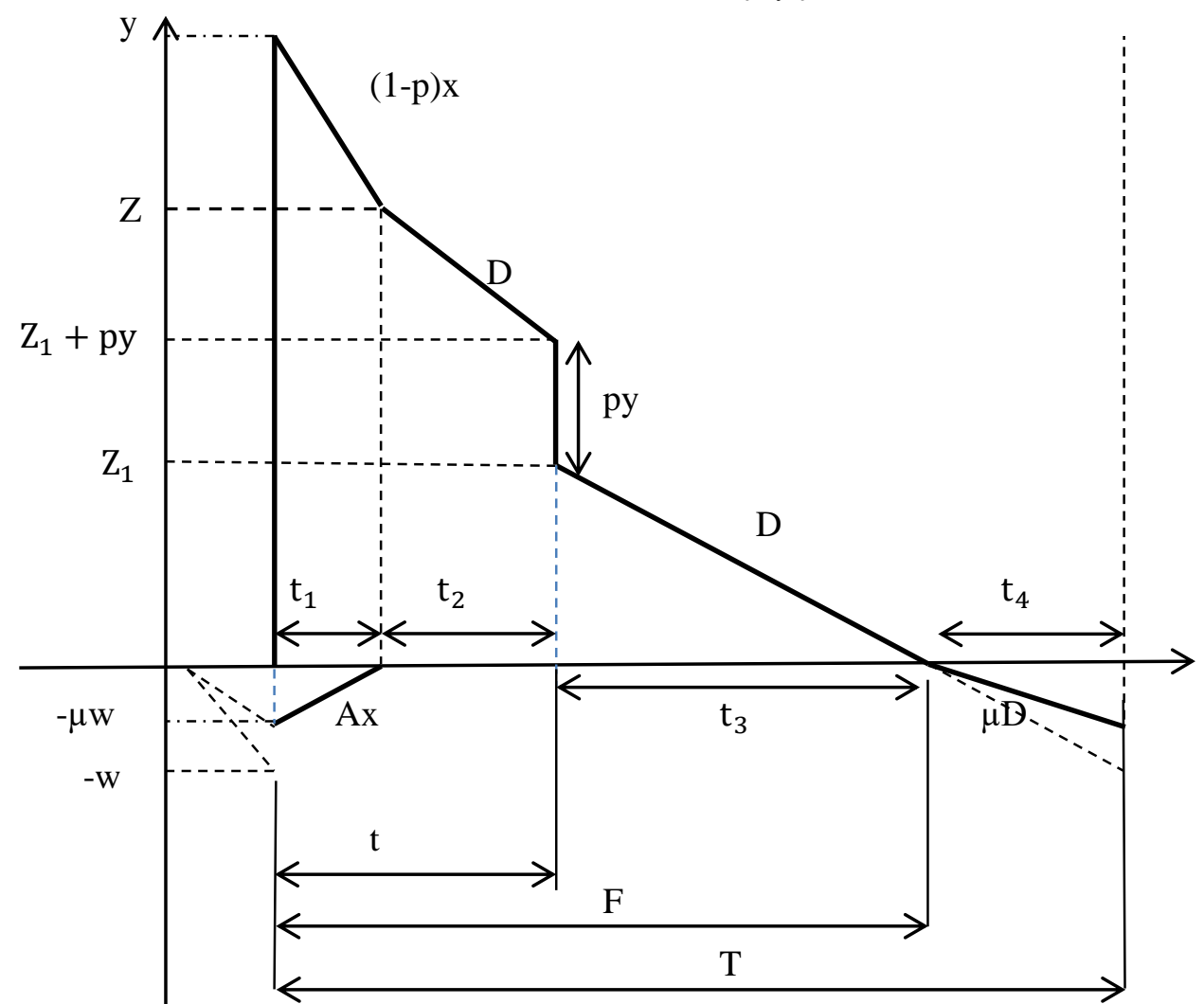

Bu durum Şekil 1'de t süresi bitiminde stok seviyesinin py kadar azaldığı şeklinde görülmektedir. $t_{1}$ süresi içerisinde hem bir önceki dönem karşılanamayan talep hem mevcut talep kusursuz ürünlerden karşılanmaktadır. Bir önceki dönem karşılanamayan talebin $t_{1}$ döneminde karşılanmasından sonra $t_{2}$ döneminde mevcut talep karşılanmaktadır. Defolu ürünlerin ayrılıp satılmasından sonra $t_{3}$ döneminde yine mevcut talep stoktaki kusursuz ürünlerden karşılanmakta ve bu sürenin sonunda eldeki stok tükenmektedir. $t_{4}$ dönemi boyunca gelen taleplerin belli bir oranı bir sonraki dönem karşılanmak üzere ertelenmektedir. Talebin tamamının ertelenmesi durumunda stoksuzluk miktarı w kadar olurken kısmi erteleme durumunda bu miktar $\mu \mathrm{w}$ kadar olmaktadır. $\mathrm{t}_{4}$ süresi sonunda tekrar sipariş verilmekte ve çevrim süresi bitmektedir.

$\mathrm{Bu}$ çalışmada önerilen bu modelde ödemelerde izin verilen gecikme süresine bağlı olarak iki durum ortaya çıkmaktadır. Bunlar: I. Durum: $(\mathrm{t}<\mathrm{M} \leq$ F) II. Durum: $(M>F)$. Çalışmanın bundan sonraki kısmında her iki durum için ayrı ayrı toplam kâr fonksiyonları elde edilerek toplam kârı maksimum yapan optimal değerleri veren formüller çıkarılacaktır. Toplam kâr fonksiyonlarında kullanılacak eşitlikler Şekil 1 kullanılarak elde edilecektir. 


\section{Durum: ( $\mathbf{t}<\mathbf{M} \leq \mathbf{F})$ İçin Modelin Elde Edilmesi}

Ödemelerde izin verilen gecikme süresinin inceleme süresi t'den büyük fakat talebin çevrim süresi içerisinde stoksuzluğa düşmeden karşılanabildiği $\mathrm{F}$ süresinden daha küçük olduğu durumu ifade etmektedir. Modelin matematiksel olarak elde edilmesinde Şekil 1'deki süreler kullanılarak toplam gelir, toplam maliyet fonksiyonları ile toplam kâr fonksiyonu elde edilmekte ve kârı maksimum yapacak sipariş miktarı ile izin verilen maksimum stoksuzluk miktarını belirlenecektir.

I. Durum için toplam gelir, $\mathrm{TR}_{1}(\mathrm{y}, \mathrm{w})$, toplam maliyet $\mathrm{TC}_{1}(\mathrm{y}, \mathrm{w})$ ve birim zamandaki toplam kâr $\operatorname{TPU}_{1}(\mathrm{y}, \mathrm{w})$, olarak alınırsa aşağıdaki eşitlikler elde edilir.

Toplam gelir; mevcut sipariş içindeki defolu ve sağlam ürünlerin satışından elde edilen gelir ile ödemelerde izin verilen gecikme süresi içerisinde satış gelirlerinin piyasa faiz oranında değerlendirilmesiyle elde edilen faiz geliri toplamından oluşmaktadır. Buradan ilgili $t$ değerleri yerine eşdeğer ifadeleri yazıldığında toplam gelir aşağıdaki gibi bulunur:

$\mathrm{TR}_{1}(\mathrm{y}, \mathrm{w})=\mathrm{s}(1-\mathrm{p}) \mathrm{y}+\mathrm{vpy}+\frac{\mathrm{sDM}^{2} \mathrm{I}_{\mathrm{e}}}{2}+\operatorname{vpy}(\mathrm{M}-\mathrm{t}) \mathrm{I}_{\mathrm{e}}=\mathrm{s}(1-\mathrm{p}) \mathrm{y}+\mathrm{vpy}+\frac{\mathrm{sDM}^{2} \mathrm{I}_{\mathrm{e}}}{2}+$ $\operatorname{vppyMI}_{\mathrm{e}}-\frac{\text { vpy }^{2} \mathrm{I}_{\mathrm{e}}}{\mathrm{x}}$

Toplam maliyet ise; sipariş, satın alma, inceleme, stok bulundurma, stok bulundurmama maliyeti ile izin verilen gecikme süresi içerisinde ödenmeyen sipariş tutarı için ortaya çıkan gecikme cezası toplamından oluşmaktadır. Buradan toplam maliyet fonksiyonu şu şekilde yazılabilir:

$\mathrm{TC}_{1}(\mathrm{y}, \mathrm{w})=\mathrm{K}+\mathrm{cy}+\mathrm{dy}+\mathrm{h}\left[\frac{\mathrm{t}_{1}(\mathrm{y}+\mathrm{Z})}{2}+\frac{\left(\mathrm{t}-\mathrm{t}_{1}\right)\left(\mathrm{Z}+\mathrm{Z}_{1}+\mathrm{py}\right)}{2}+\frac{\mathrm{t}_{3} \mathrm{Z}_{1}}{2}\right]+\frac{\pi\left(\mathrm{t}_{1}+\mathrm{t}_{4}\right) \mu \mathrm{w}}{2}+$ $\mathrm{c}\left(\frac{(1-\mathrm{p}) \mathrm{y}-\mu \mathrm{w}-\mathrm{DM}}{2}\right)\left(\mathrm{T}-\mathrm{t}_{4}-\mathrm{M}\right) \mathrm{I}_{\mathrm{e}}$

$\mathrm{t}$ değerleri için eşdeğer ifadeleri yerlerine yazılırsa; $\mathrm{TC}_{1}(\mathrm{y}, \mathrm{w})$ fonksiyonu aşağıdaki gibi elde edilir:

$$
\begin{aligned}
& \mathrm{TC}_{1}(\mathrm{y}, \mathrm{w})=\mathrm{K}+\frac{\mathrm{CDM}^{2} \mathrm{I}_{\mathrm{O}}}{2}+\frac{\mathrm{cMI}_{\mathrm{O}} \mathrm{w}(1+\mu)}{2}-\mathrm{c}(1-\mathrm{p}) \mathrm{MI}_{\mathrm{O}} \mathrm{y}+(\mathrm{c}+\mathrm{d}) \mathrm{y}+ \\
& \frac{\left(\pi+\mathrm{cI} \mathrm{I}_{\mathrm{O}}\right)}{2 \mathrm{D}} \mu \mathrm{w}^{2}+\frac{(1-\mathrm{p})^{2} \mathrm{cI}_{\mathrm{O}}}{2 \mathrm{D}} \mathrm{y}^{2}-\left[\frac{(1-\mathrm{p})\left(2 \mathrm{~h} \mu+\mathrm{cI} \mathrm{O}_{\mathrm{O}}(1+\mu)\right.}{2 \mathrm{D}}\right] \mathrm{yw}+\left[\frac{\mathrm{hE_{2 }}}{2 \mathrm{D}}+\frac{\pi}{2 \mathrm{x}(1-\mathrm{p})-\mathrm{D}}\right] \mu^{2} \mathrm{w}^{2}+ \\
& \frac{\mathrm{h}}{2 \mathrm{D}}\left[\frac{\mathrm{D}(2-\mathrm{D} / \mathrm{x})}{\mathrm{x}}+(1-\mathrm{p}-\mathrm{D} / \mathrm{x})^{2}\right] \mathrm{y}^{2}
\end{aligned}
$$

Rassal bir değişken olan defolu ürün oranı $p$ 'nin çevrim süresi ve toplam kâr fonksiyonlarını da rassal yapacağından birim zamandaki toplam kârın da beklenen değeri toplam gelir ile toplam maliyet fonksiyonlarının beklenen değerleri arasındaki farkın çevrim süresinin beklenen değerine bölünmesiyle aşağıdaki gibi yazılabilir:

$$
\begin{aligned}
& \mathrm{E}\left(\mathrm{TPU}_{1}\right)=\frac{\mathrm{E}\left(\mathrm{TR}_{1}\right)-\mathrm{E}\left(\mathrm{TC}_{1}\right)}{\mathrm{E}(\mathrm{T})}=\left[\mathrm{S}+\mathrm{cMI} \mathrm{I}_{\mathrm{O}}+\frac{\mathrm{vE}(\mathrm{p})\left(1+\mathrm{MI}_{\mathrm{e}}\right)-\mathrm{c}-\mathrm{d}}{\mathrm{E}_{1}}\right] \mathrm{D}-\left[\frac{\mathrm{vE}(\mathrm{p}) \mathrm{DI}_{\mathrm{e}}}{\mathrm{x}}+\right. \\
& \left.\frac{\mathrm{hE}_{4}+\mathrm{cI}_{\mathrm{O}} \mathrm{E}_{5}}{2}\right] \frac{\mathrm{y}}{\mathrm{E}_{1}}-\left[\left(\pi+\mathrm{cI} \mathrm{I}_{\mathrm{O}}\right) \mu+\left(\mathrm{hE}_{2}+\frac{\pi \mathrm{D}}{\mathrm{x}(1-\mathrm{p})-\mathrm{D}}\right) \mu^{2}\right] \frac{\mathrm{w}^{2}}{2 \mathrm{E}_{1} \mathrm{y}}-\left[\left(\mathrm{cI}_{\mathrm{O}}-\mathrm{SI}_{\mathrm{e}}\right)(\mathrm{DM})^{2}+\right. \\
& 2 \mathrm{KD}] \frac{1}{2 \mathrm{E}_{1} \mathrm{y}}-\frac{\mathrm{cDMI} \mathrm{O}_{\mathrm{O}}(1+\mu) \mathrm{w}}{2 \mathrm{E}_{1} \mathrm{y}}+\frac{2 \mathrm{h \mu} \mu \mathrm{cI} \mathrm{I}_{\mathrm{O}}(1+\mu)}{2} \mathrm{~W} \\
& \quad \text { Burada; } \\
& \mathrm{E}_{1}=\mathrm{E}(1-\mathrm{p})=1-\mathrm{E}(\mathrm{p})
\end{aligned}
$$




$$
\begin{aligned}
& \mathrm{E}_{2}=\mathrm{E}\left[\frac{1-\mathrm{p}}{1-\mathrm{p}-\mathrm{D} / \mathrm{x}}\right] \\
& \mathrm{E}_{3}=\mathrm{E}\left[(1-\mathrm{p}-\mathrm{D} / \mathrm{x})^{2}\right] \\
& \mathrm{E}_{4}=\frac{\mathrm{D}(2-\mathrm{D} / \mathrm{x})}{\mathrm{x}}+\mathrm{E}_{3} \\
& \mathrm{E}_{5}=\mathrm{E}\left[(1-\mathrm{p})^{2}\right] \text { olarak alınmaktadır }
\end{aligned}
$$

Optimal sipariş miktarı ve izin verilen maksimum stoksuzluk miktarı, birim zamandaki beklenen kâr fonksiyonu, E(TPU $\left.{ }_{1}\right)$ 'nun sipariş miktarı y ve stoksuzluk miktarı w'ye göre kısmi türevleri alınarak aşağıdaki gibi bulunur:

$$
\begin{aligned}
& \mathrm{y}_{1}^{*}=\sqrt{\frac{\left[\left(\pi+\mathrm{cI}_{\mathrm{O}}\right) \mu+\left(\mathrm{hE}_{2}+\frac{\pi \mathrm{D}}{\mathrm{x}(1-\mathrm{p})-\mathrm{D}}\right) \mu^{2}\right] \mathrm{w}^{2}+\left(\mathrm{cI}_{\mathrm{O}}-\mathrm{SI}_{\mathrm{e}}\right) \mathrm{D}^{2} \mathrm{M}^{2}+2 \mathrm{KD}+\frac{\mathrm{cDMI}(1+\mu) \mathrm{w}}{2}}{\frac{2 \mathrm{VE}(\mathrm{p}) \mathrm{DI}_{\mathrm{e}}}{\mathrm{x}}+\mathrm{hE}_{4}+\mathrm{cI}_{\mathrm{O}} \mathrm{E}_{5}}} \\
& \mathrm{w}_{1}^{*}=\frac{\left(\frac{2 \mathrm{~h} \mu+\mathrm{cI}_{\mathrm{O}}(1+\mu)}{2}\right) \mathrm{E}_{1} \mathrm{y}_{1}^{*}-\left(\frac{\mathrm{cDMI} \mathrm{O}(1+\mu)}{2}\right)}{\left(\pi+\mathrm{cI}_{\mathrm{O}}\right) \mu+\left(\mathrm{hE}_{2}+\frac{\pi \mathrm{D}}{\mathrm{x}(1-\mathrm{p})-\mathrm{D}}\right) \mu^{2}}
\end{aligned}
$$

$\mathrm{w}_{1}^{*}$ değeri (5) no'lu eşitlikte yerine yazılırsa; $\mathrm{y}_{1}^{*}$ değeri $\mathrm{w}_{1}^{*}$ değerinden bağımsız olarak aşağıdaki gibi bulunur:

$$
\mathrm{y}_{1}^{*}=\sqrt{\frac{2 \mathrm{KD}+\left(\mathrm{cI}_{\mathrm{O}}-\mathrm{SI}_{\mathrm{e}}\right)(\mathrm{DM})^{2}-\frac{\left(\frac{\mathrm{cDMI}_{\mathrm{O}}(1+\mu)}{2}\right)^{2}}{\left(\pi+\mathrm{cI}_{\mathrm{O}}\right) \mu+\left(\mathrm{hE}_{2}+\frac{\pi \mathrm{D}}{\mathrm{x}(1-\mathrm{p})-\mathrm{D}}\right) \mu^{2}}}{\frac{2 \mathrm{vE}(\mathrm{p}) \mathrm{DI}_{\mathrm{e}}}{\mathrm{x}}+\mathrm{hE}_{4}+\mathrm{cI}_{\mathrm{O}} \mathrm{E}_{5}-\frac{\left(\frac{2 \mathrm{~h} \mu+\mathrm{cI}_{\mathrm{O}}(1+\mu)}{2}\right)^{2} \mathrm{E}_{1}^{2}}{\left(\pi+\mathrm{cI}_{\mathrm{O}}\right) \mu+\left(\mathrm{hE}_{2}+\frac{\pi \mathrm{D}}{\mathrm{x}(1-\mathrm{p})-\mathrm{D}}\right) \mu^{2}}}}
$$

\section{Durum: $(M>F)$ İçin Modelin Elde Edilmesi}

I. Durum için toplam gelir, $\mathrm{TR}_{1}(\mathrm{y}, \mathrm{w})$, toplam maliyet $\mathrm{TC}_{1}(\mathrm{y}, \mathrm{w})$ ve birim zamandaki toplam kâr $\operatorname{TPU}_{1}(\mathrm{y}, \mathrm{w})$, olarak alınırsa aşağıdaki eşitlikler elde edilir.

Toplam gelir; defolu ve kusursuz ürünlerin satış geliri ile izin verilen gecikme süresi içerisinde satış gelirlerinin piyasa faiz oranından değerlendirilmesiyle elde edilen faiz geliri toplamından oluşmaktadır. Buna göre toplam gelir fonksiyonu aşağıdaki gibi yazılabilir:

$\mathrm{TR}_{2}(\mathrm{y}, \mathrm{w})=\mathrm{s}(1-\mathrm{p}) \mathrm{y}+\mathrm{vpy}+\frac{\mathrm{s}[(1-\mathrm{p}) \mathrm{y}-\mu \mathrm{w}]\left(\mathrm{t}+\mathrm{t}_{3}\right) \mathrm{I}_{\mathrm{e}}}{2}+\mathrm{s}[(1-\mathrm{p}) \mathrm{y}-\mu \mathrm{w}](\mathrm{M}-$

$\left.t_{3}-t\right) I_{e}+v p y(M-t) I_{e}=[s(1-p)+v p]\left(1+M I_{e}\right) y-\left[\frac{v p I_{e}}{x}+\frac{s I_{e}(1-p)^{2}}{2 D}\right] y^{2}+$ $\frac{\mathrm{sI}_{\mathrm{e}}(1-\mathrm{p}) \mathrm{y} \mu \mathrm{w}}{\mathrm{D}}-\mathrm{sMI}_{\mathrm{e}} \mu \mathrm{w}-\frac{\mathrm{sI}_{\mathrm{e}}}{2 \mathrm{D}} \mu^{2} \mathrm{w}^{2}$

Toplam maliyet ise; sipariş, satın alma, inceleme, stok bulundurma, stok bulundurmama maliyetleri toplamından oluşmaktadır. Buradan toplam maliyet fonksiyonu şu şekilde elde edilir:

$\mathrm{TC}_{2}(\mathrm{y}, \mathrm{w})=\mathrm{K}+\mathrm{cy}+\mathrm{dy}+\mathrm{h}\left[\frac{\mathrm{t}_{1}(\mathrm{y}+\mathrm{Z})}{2}+\frac{\left(\mathrm{t}-\mathrm{t}_{1}\right)\left(\mathrm{Z}+\mathrm{Z}_{1}+\mathrm{py}\right)}{2}+\frac{\mathrm{t}_{3} \mathrm{Z}_{1}}{2}\right]+\frac{\pi\left(\mathrm{t}_{1}+\mathrm{t}_{4}\right) \mu \mathrm{w}}{2}=$

$\mathrm{K}+\mathrm{cy}+\mathrm{cd}+\frac{\mathrm{h}}{2 \mathrm{D}}\left[\frac{\mathrm{D}(2-\mathrm{D} / \mathrm{x})}{\mathrm{x}}+(1-\mathrm{p}-\mathrm{D} / \mathrm{x})^{2}\right] \mathrm{y}^{2}+\left[\frac{\mathrm{h}(1-\mathrm{p})}{2 \mathrm{D}(1-\mathrm{p}-\mathrm{D} / \mathrm{x})}+\right.$

$\left.\frac{\pi \mathrm{D}\left(\mu^{2}+\mathrm{x}(1-\mathrm{p})-\mu\right)}{2 \mathrm{Dx}(1-\mathrm{p})-\mathrm{D}}\right] \mathrm{w}^{2}-\frac{\mathrm{h}(1-\mathrm{p})}{\mathrm{D}} \mathrm{y} \mu \mathrm{w}$

Birim zamanda beklenen toplam kâr fonksiyonu ise I. Durumdaki gibi beklenen değerler kullanılarak şu şekilde elde edilir. 


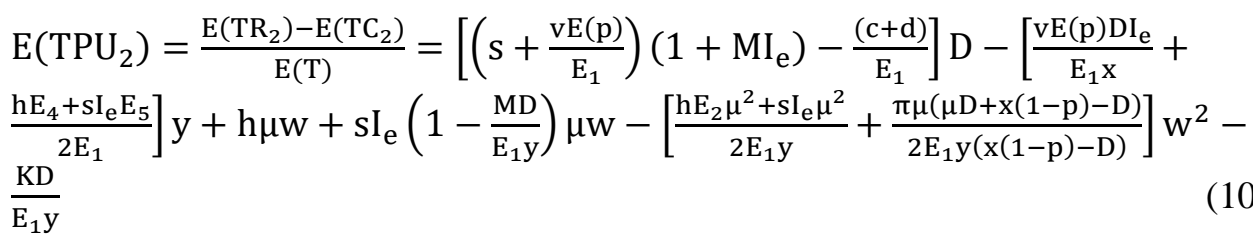

$\mathrm{Bu}$ eşitliklerde;

$\mathrm{E}_{1}=\mathrm{E}(1-\mathrm{p})=1-\mathrm{E}(\mathrm{p})$

$\mathrm{E}_{2}=\mathrm{E}\left[\frac{1-\mathrm{p}}{1-\mathrm{p}-\mathrm{D} / \mathrm{x}}\right]$

$\mathrm{E}_{3}=\mathrm{E}\left[(1-\mathrm{p}-\mathrm{D} / \mathrm{x})^{2}\right]$

$\mathrm{E}_{4}=\frac{\mathrm{D}(2-\mathrm{D} / \mathrm{x})}{\mathrm{x}}+\mathrm{E}_{3}$

$\mathrm{E}_{5}=\mathrm{E}\left[(1-\mathrm{p})^{2}\right]$ olarak alınmaktadır.

Optimal sipariş miktarı ve izin verilen maksimum stoksuzluk miktarı, birim zamandaki beklenen kâr fonksiyonunun sipariş miktarı y ve stoksuzluk miktarı w'ye göre kısmi türevleri alınarak aşağıdaki gibi bulunur:

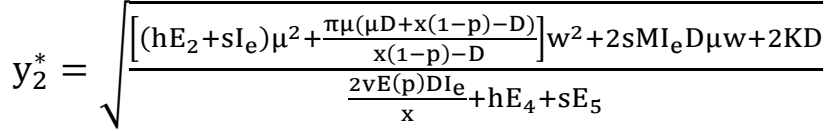

$$
\begin{aligned}
& \mathrm{w}_{2}^{*}=\frac{\left(h \mu+\mathrm{sI}_{\mathrm{e}} \mu\right) \mathrm{E}_{1} \mathrm{y}_{1}^{*}-\mathrm{sMI} \mathrm{e}_{\mathrm{e}} \mathrm{D} \mu}{\left[\left(\mathrm{hE}_{2}+\mathrm{sI}_{\mathrm{e}}\right) \mu^{2}+\frac{\pi \mu(\mu \mathrm{D}+\mathrm{x}(1-\mathrm{p})-\mathrm{D})}{\mathrm{x}(1-\mathrm{p})-\mathrm{D}}\right]}
\end{aligned}
$$

olur:

$\mathrm{w}_{2}^{*}$ değeri (11) no'lu eşitlikte yerine yazılırsa; $\mathrm{y}_{2}^{*}$ değeri aşă̆ıdaki gibi

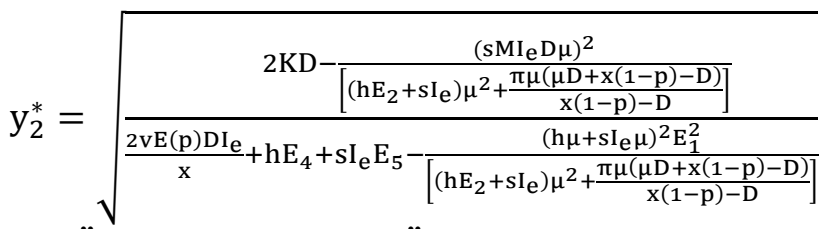

\section{C. Önerilen Modelden Önceki Çalışmaların Elde Edilmesi}

$\mathrm{Bu}$ çalışmada önerilen model genel bir model olup bu konuda daha önce yapılmış çalışmalar bu modelin özel durumları olarak elde edilebilir. $\mathrm{Bu}$ çalışmalardan örnek olarak üç tanesi aşağıda açıklanmaktadır.

\section{i. Sulak (2008) Modeli}

Sulak (2008) geliştirdiği modelde ödemelerde gecikme, defolu ürün ve stoksuzluk durumunu ele almıştır. Bu çalışmada geliştirilen modelde erteleme oranı $\mu=1$ olarak alınırsa (6), (7), (12) ve (13) nolu eşitliklerdeki optimal değerler Sulak (2008)'in bulduğu aşağıdaki sonuçlara dönüşecektir. Dolayısıyla Sulak (2008) modeli bu çalışmada geliştirilen modelin özel bir durumudur.

$$
\mathrm{y}_{1}^{*}=\sqrt{\frac{2 \mathrm{KD}+\left(\mathrm{cI}_{\mathrm{O}}-\mathrm{SI}_{\mathrm{e}}\right)(\mathrm{DM})^{2}-\frac{(\mathrm{cDMI})^{2}}{(\mathrm{~h}+\pi) \mathrm{E}_{2}+\mathrm{cI}_{0}}}{\frac{2 \mathrm{vE}(\mathrm{p}) \mathrm{DI}_{\mathrm{e}}}{\mathrm{x}}+\mathrm{hE}_{4}+\mathrm{cI}_{\mathrm{O}} \mathrm{E}_{5}-\frac{\left(\mathrm{h}+\mathrm{cI}_{0}\right)^{2} \mathrm{E}_{1}^{2}}{(\mathrm{~h}+\pi) \mathrm{E}_{2}+\mathrm{cI} \mathrm{I}_{0}}}} \quad \mathrm{w}_{1}^{*}=\frac{\left(\mathrm{h}+\mathrm{cI}_{0}\right) \mathrm{E}_{1} \mathrm{y}_{1}^{*}-\left(\mathrm{cDMI}_{\mathrm{O}}\right)}{(\mathrm{h}+\pi) \mathrm{E}_{2}+\mathrm{cI}_{0}}
$$




$$
\mathrm{y}_{2}^{*}=\sqrt{\frac{2 \mathrm{KD}-\frac{\left(\mathrm{sMI} \mathrm{e}_{\mathrm{e}}\right)^{2}}{(\mathrm{~h}+\pi) \mathrm{E}_{2}+s \mathrm{se}_{\mathrm{e}}}}{\frac{2 \mathrm{vE}(\mathrm{p}) \mathrm{DI}_{\mathrm{e}}}{\mathrm{x}}+\mathrm{hE}_{4}+\mathrm{sI}_{\mathrm{e}} \mathrm{E}_{5}-\frac{\left(\mathrm{h}+\mathrm{sI}_{\mathrm{e}}\right)^{2} \mathrm{E}_{1}^{2}}{(\mathrm{~h}+\pi) \mathrm{E}_{2}+\mathrm{sI}_{\mathrm{e}}}}} \quad \mathrm{w}_{2}^{*}=\frac{\left(\mathrm{h}+\mathrm{sI}_{\mathrm{e}}\right) \mathrm{E}_{1} \mathrm{y}_{1}^{*}-\mathrm{sMI}_{\mathrm{e}} \mathrm{D}}{(\mathrm{h}+\pi) \mathrm{E}_{2}+\mathrm{sI}_{\mathrm{e}}}
$$

\section{ii. Stoksuzluk Durumunda Klasik Ekonomik Sipariş Miktarı Modeli}

Önerilen modelde defolu ürün olması ve ödemelerde gecikmeye izin verilmesi varsayımı kaldırılırsa model Klasik Ekonomik Sipariş Miktarı modellerinde stoksuzluğa izin verilmesi durumunu ele alan modele dönüşür. Yani, matematiksel modelde (6), (7), (12) ve (13) nolu eşitliklerde $p=M=0$ ise $\mathrm{I}_{\mathrm{e}}=\mathrm{I}_{\mathrm{o}}=0, \mathrm{E}_{1}=\mathrm{E}_{2}=\mathrm{E}_{3}=\mathrm{E}_{4}=\mathrm{E}_{5}=\mu=1$ ve $\mathrm{x}=\infty$ olur. Bu durumda bu eşitlikler Klasik Ekonomik Sipariş Miktarı modelinde elde edilen aşağıdaki eşitliklere dönüşecektir.

$$
\begin{aligned}
& \mathrm{y}_{1}^{*}=\mathrm{y}_{2}^{*}=\mathrm{y}^{*}=\sqrt{\frac{2 \mathrm{KD}(\mathrm{h}+\pi)}{\mathrm{h} \pi}}=\sqrt{\frac{2 \mathrm{KD}}{\mathrm{h}} \frac{(\mathrm{h}+\pi)}{\pi}} \quad \mathrm{w}_{1}^{*}=\mathrm{w}_{2}^{*}= \\
& \mathrm{w}^{*}=\frac{\mathrm{hy}^{*}}{(\mathrm{~h}+\pi)}
\end{aligned}
$$

Böylece stoksuzluk durumunda ekonomik sipariş miktarı modeli bu çalışmanın özel bir durumu olarak önerilen modelden elde edilebilmektedir.

\section{iii. Klasik Ekonomik Sipariş Miktarı Modeli}

Önerilen modelde, talebin ertelenmesi (stoksuzluğa izin verilmesi), defolu ürün ve ödemelerde gecikmeye izin verme varsayımları yapılmazsa, yani $p=B=M=I_{e}=I_{o}=0$ ve $x=\pi=\infty$ ise: (6), (7), (12) ve (13) nolu eşitlikler aşağıdaki temel Ekonomik Sipariş Miktarı modelini verecektir:

$$
\mathrm{y}_{1}^{*}=\mathrm{y}_{2}^{*}=\mathrm{y}^{*}=\sqrt{\frac{2 \mathrm{KD}}{\mathrm{h}}} \quad \mathrm{w}_{1}^{*}=\mathrm{w}_{2}^{*}=\mathrm{w}^{*}=0
$$

$\mathrm{Bu}$ sonuçlar göstermektedir ki, bu çalışmada geliştirilen model stoksuzluk durumunda talebin ertelenmesi, ödemelerde gecikmeye izin verilmesi ve defolu ürün durumlarını ele alan modellerin en genel halidir. Önerilen modeldeki ilave varsayımların çıkarılmasıyla bu model Stoksuzluk Durumuna İzin Veren Klasik Ekonomik Sipariş Miktarı modeli ve Klasik Ekonomik Sipariş Miktarı modeline dönüşecektir. Dolayısıyla bu modeller bu çalışmada önerilen modelin özel durumları olarak ifade edilebilir.

\section{Nümerik Örnekler}

Modelin geçerliliği ve optimal değerlerin bulunması için iki nümerik örnek çözülecektir.

\section{i. I. Durum İçin Nümerik Örnek} kullanılacaktır:

Modelin geçerliliği için yapılacak hesaplamalarda aşağıdaki veriler

Defolu ürün oranı olasılık yoğunluk fonksiyonu $f(p)=$ $\left\{\begin{array}{cc}10, & 0 \leq \mathrm{p} \leq 0.1 \\ 0 & \text { aksi halde }\end{array}\right.$, Talep $=4000$ birim $/ \mathrm{y} 1$ l, inceleme oran $=50000$ birim $/ \mathrm{y} 1$, sipariş maliyeti $=400 \mathrm{TL} /$ sipariş, stok bulundurma maliyeti $=5 \mathrm{TL} / \mathrm{birim}$, stok bulundurmama (erteleme) maliyeti $=4 \mathrm{TL} / \mathrm{birim}$, satın alma maliyeti $=30 \mathrm{TL} / \mathrm{birim}$, ürün inceleme maliyeti=1.5 TL/birim, kusursuz ürünlerin satış fiyatı $50 \mathrm{TL} / \mathrm{birim}$, 
defolu ürünlerin satış fiyatı $=20 \mathrm{TL} /$ birim, ödemelerde izin verilen gecikme süresi $=30$ gün $=0.083 \mathrm{yl}$, mevduat hesabı için yıllık faiz oranı $=\% 10$, piyasa yıllık faiz oran $1=\% 12$, karşılanamayan talebin erteleme (stoksuzluk) oranı $=0.5^{\prime}$ tir.

Buna göre nümerik örnekte kullanılacak parametreler simgeleriyle aşağıdaki gibi yazılabilir:

$\mathrm{D}=4,000$ birim, $\mathrm{x}=50,000$ birim, $\mathrm{K}=400 \mathrm{TL}, \mathrm{h}=5 \mathrm{TL}, \mathrm{p}=4 \mathrm{TL}, \mathrm{c}=$ $30 \mathrm{TL}, \mathrm{d}=1.5 \mathrm{TL}, \mathrm{s}=50 \mathrm{TL}, \mathrm{v}=20 \mathrm{TL}, \mathrm{M}=0.083 \mathrm{y} 1 \mathrm{l}, \mathrm{Ie}=0.10$, Io $=0.12$, $\mu=0.5$.

Defolu ürün oranı rassal değişken olduğundan optimal değerleri veren formüllerde ilgili beklenen değerler;

$$
E(p)=0.05, \quad E_{1}=0.95, \quad E_{2}=1.092055 \quad E_{3}=0.757733 \quad E_{4}=
$$
$0.91133, \mathrm{E}_{5}=0.90333$ olarak hesaplanır.

Bu değerler (6), (7), (12) ve (13) nolu eşitliklerde yerine yazıldığında; optimal değerler aşağıdaki gibi elde edilmiştir:

$$
\begin{aligned}
& \mathrm{y}_{1}^{*} \cong 953 \text { birim } \\
& \mathrm{w}_{1}^{*} \cong 724 \text { birim } \\
& \mathrm{T}_{1}^{*}=0.226 \cong 81 \text { gün } \\
& \mathrm{E}\left[\mathrm{TPU}_{1}\left(\mathrm{y}_{1}^{*}, \mathrm{w}_{1}^{*}\right)\right] \cong 68731 \mathrm{TL} \\
& \mathrm{F}_{1}^{*}=0.135 \text { yll } \cong 49 \text { gün } \\
& \mathrm{t}=0.0191 \text { yll } \cong 7 \text { gün }
\end{aligned}
$$

$\mathrm{Bu}$ sonuçlar model analizinde ödemelerde izin verilen gecikme süresinin inceleme süresinden büyük, talebin normal olarak stoksuzluğa düşmeden karşılanabildiği süreden küçük olduğu I. Duruma uymaktadır. (Yani $(t<M \leq F)$ Dolayısıyla I. Durum için elde edilen bu değerler optimal değerlerdir.

\section{ii. II. Durum İçin Nümerik Örnek}

Birinci durumda kullanılan aynı veriler sadece ödemelerde gecikmeye izin verilen sürenin 30 gün yerine 60 gün alınması şeklinde güncellenerek optimal değerler hesaplanacaktır. (Bu durumda I. Durum için kullanılan değişkenlerden sadece $M=\frac{60}{360}=0.166$ olarak değişir. Diğer değişkenler sabittir.) Bu durumda optimal değerler aşağıdaki gibi bulunur:

$$
\begin{aligned}
& \mathrm{y}_{2}^{*} \cong 779 \text { birim } \\
& \mathrm{w}_{2}^{*} \cong 432 \text { birim } \\
& \mathrm{T}_{2}^{*}=0.185 \cong 67 \text { gün } \\
& \mathrm{E}\left[\mathrm{TPU}_{2}\left(\mathrm{y}_{2}^{*}, \mathrm{w}_{2}^{*}\right)\right] \cong 69687 \mathrm{TL} \\
& \mathrm{F}_{2}^{*}=0.131 \text { yll } \cong 47 \text { gün }
\end{aligned}
$$

$\mathrm{Bu}$ sonuçlar model analizinde ödemelerde izin verilen gecikme süresinin talebin normal olarak stoksuzluğa düşmeden karşılanabildiği süreden büyük olduğu II. Duruma uymaktadır. (Yani (M > F) Dolayısıyla II. Durum için elde edilen bu değerler optimal değerlerdir.

\section{DUYARLILIK ANALIZI}

Duyarlılık analizi önerilen modeldeki temel parametrelerdeki değişimin optimal değerler üzerindeki etkisinin araştırılmasında kullanılan önemli bir araçtır. Bu çalışmada elde edilen modelde üç önemli parametre ele alınmıştır. 
Bunlar: talebin erteleme oran1, ödemelerde izin verilen gecikme süresi ve defolu ürün oranıdır. $\mathrm{Bu}$ üç parametredeki değişimlerin optimal değerler üzerindeki etkileri ile ilgili olarak aşağıdaki sonuçlara ulaşılmıştır.

- Talebin erteleme oranı arttıkça optimal sipariş miktarı, toplam kâr ve optimal çevrim süresi çok anlamlı olmamakla birlikte önce azalmakta daha sonra ise artmaktadır. Belli bir erteleme oranında bu değerler minimum değere sahiptir. Bu çalışmada erteleme oranının 0,4 olduğu durumda optimal sipariş miktarı ve çevrim süresi en düşük değere ulaşmaktadır. Talebin normal olarak stoktan karşılandığı süre ile izin verilen maksimum stoksuzluk miktarı ise stoksuzluk oranı arttıkça anlamlı bir düzeyde azalmaktadır.

- Optimal sipariş miktarı, izin verilen maksimum stoksuzluk miktarı ve optimal çevrim süresi ile ödemelerde izin verilen gecikme süresi arasında negatif ilişki olup izin verilen gecikme süresi arttıkça bu değerler anlamlı bir düzeyde azalmaktadır. Diğer taraftan ödemelerde izin verilen gecikme süresi arttıkça toplam kâr ile talebin normal olarak stoktan karşılandığı sürede çok anlamlı olmayan artışlar görülmektedir.

- Defolu ürün oranı arttıkça optimal sipariş miktarı anlamlı düzeyde artmakta bunun dışındaki diğer değişkenler ise anlamlı düzeyde azalmaktadır. Yani izin verilen maksimum stoksuzluk miktarı, toplam kâr, optimal çevrim süresi ve talebin normal olarak stoksuzluğa düşmeden karşılandığı süre defolu ürün oranı arttıkça duyarlı bir şekilde azalmaktadır.

Çalışmada ayrıca üç temel parametre olan talebin erteleme oranı, izin verilen gecikme süresi ve defolu ürün oranının aynı anda değişimlerinin optimal değerler üzerindeki eşanlı etkisi de analiz edilmiştir. $\mathrm{Bu}$ amaçla, her bir parametrenin dört farklı değeri için optimal sipariş miktarı, stoksuzluk miktarı ve optimal toplam kâr değerleri hesaplanmıştır. Bulunan sonuçlar Tablo 2'de sunulmuştur.

Tablo değerlerinden optimal sipariş miktarı ve toplam kâr değerleriyle ilgili olarak şu sonuçlar çıkarılabilir:

\section{A. Optimal Sipariş \\ Miktarındaki \\ Değişimlerle \\ İlgili}

\section{Değerlendirmeler:}

Optimal sipariş miktarı ödemelerde izin verilen gecikme süresi azaldıkça ve defolu ürün oranının beklenen değeri arttıkça artmaktadır. Diğer taraftan optimal sipariş miktarı stoksuzluk oranı arttıkça önce azalmakta sonra artmakta, defolu ürün oranı arttıkça artmaktadır. 
Tablo 2: Erteleme Oranı, Ödemelerde İzin Verilen Gecikme Süresi ve Defolu Ürün Oranının Farklı Değerleri için Optimal Değerler

\begin{tabular}{|c|c|c|c|c|c|c|c|c|c|c|c|}
\hline \multicolumn{3}{|c|}{ Parametreler } & \multicolumn{3}{|c|}{ Optimal Değerler } & \multicolumn{3}{|c|}{ Parametreler } & \multicolumn{3}{|c|}{ Optimal Değerler } \\
\hline$\mu$ & $\mathbf{M}$ & $\mathbf{E}(\mathbf{p})$ & $\mathbf{y}^{*}$ & $\mathbf{w}^{*}$ & $\mathbf{E}(\mathbf{T P U}) *$ & $\mu$ & $\mathbf{M}$ & $\mathbf{E}(\mathbf{p})$ & $\mathbf{y}^{*}$ & $\mathbf{w}^{*}$ & $\mathbf{E}(\mathbf{T P U}) *$ \\
\hline \multirow{16}{*}{0.3} & \multirow{4}{*}{15} & 0.05 & 1004 & 1167 & 68407 & & \multirow{4}{*}{15} & 0.05 & 1009 & 707 & 68522 \\
\hline & & 0.15 & 1081 & 1114 & 62626 & & & 0.15 & 1083 & 672 & 62735 \\
\hline & & 0.25 & 1146 & 1029 & 55234 & & & 0.25 & 1146 & 617 & 55333 \\
\hline & & 0.35 & 1190 & 904 & 45468 & & & 0.35 & 1186 & 539 & 45555 \\
\hline & \multirow{4}{*}{30} & 0.05 & 958 & 968 & 68640 & & \multirow{4}{*}{30} & 0.05 & 974 & 618 & 68843 \\
\hline & & 0.15 & 1031 & 918 & 62908 & & & 0.15 & 1046 & 584 & 63104 \\
\hline & & 0.25 & 1094 & 838 & 55581 & & & 0.25 & 1107 & 532 & 55766 \\
\hline & & 0.35 & 1136 & 720 & 45906 & & & 0.35 & 1146 & 458 & 46076 \\
\hline & \multirow{4}{*}{45} & 0.05 & 876 & 722 & 68991 & 0.1 & \multirow{4}{*}{45} & 0.05 & 913 & 509 & 69249 \\
\hline & & 0.15 & 942 & 677 & 63312 & & & 0.15 & 980 & 478 & 63561 \\
\hline & & 0.25 & 1000 & 605 & 56058 & & & 0.25 & 1011 & 431 & 56282 \\
\hline & & 0.35 & 1039 & 499 & 46487 & & & 0.35 & 1054 & 363 & 46668 \\
\hline & \multirow{4}{*}{60} & 0.05 & 715 & 478 & 69571 & & \multirow{4}{*}{60} & 0.05 & 834 & 396 & 69777 \\
\hline & & 0.15 & 781 & 454 & 63949 & & & 0.15 & 900 & 370 & 64137 \\
\hline & & 0.25 & 849 & 414 & 56767 & & & 0.25 & 958 & 327 & 56927 \\
\hline & & 0.35 & 911 & 349 & 47287 & & & 0.35 & 999 & 264 & 47406 \\
\hline \multirow{16}{*}{0.5} & \multirow{4}{*}{15} & 0.05 & 991 & 845 & 68433 & \multirow{16}{*}{0.9} & \multirow{4}{*}{15} & 0.05 & 1034 & 624 & 68618 \\
\hline & & 0.15 & 1066 & 806 & 62651 & & & 0.15 & 1107 & 591 & 62824 \\
\hline & & 0.25 & 1131 & 744 & 55257 & & & 0.25 & 1167 & 540 & 55413 \\
\hline & & 0.35 & 1176 & 653 & 45490 & & & 0.35 & 1202 & 468 & 45623 \\
\hline & \multirow{4}{*}{30} & 0.05 & 953 & 724 & 68731 & & \multirow{4}{*}{30} & 0.05 & 1001 & 553 & 68949 \\
\hline & & 0.15 & 1025 & 687 & 62997 & & & 0.15 & 1071 & 521 & 63204 \\
\hline & & 0.25 & 1089 & 628 & 55667 & & & 0.25 & 1129 & 472 & 55857 \\
\hline & & 0.35 & 1132 & 542 & 45988 & & & 0.35 & 1163 & 404 & 46155 \\
\hline & \multirow{4}{*}{45} & 0.05 & 887 & 577 & 69125 & & \multirow{4}{*}{45} & 0.05 & 937 & 466 & 69359 \\
\hline & & 0.15 & 954 & 543 & 63443 & & & 0.15 & 1004 & 436 & 63660 \\
\hline & & 0.25 & 1014 & 489 & 56183 & & & 0.25 & 1059 & 389 & 56369 \\
\hline & & 0.35 & 1055 & 410 & 46603 & & & 0.35 & 1091 & 323 & 46735 \\
\hline & \multirow{4}{*}{60} & 0.05 & 779 & 432 & 69687 & & \multirow{4}{*}{60} & 0.05 & 882 & 367 & 69848 \\
\hline & & 0.15 & 846 & 407 & 64056 & & & 0.15 & 945 & 340 & 64201 \\
\hline & & 0.25 & 909 & 365 & 56859 & & & 0.25 & 998 & 297 & 56980 \\
\hline & & 0.35 & 961 & 301 & 47356 & & & 0.35 & 1030 & 236 & 47444 \\
\hline
\end{tabular}

* Tabloda koyu ile yazılan optimal değerler II. duruma uyan değerleri göstermektedir.

Benzer şekilde ödemelerde izin verilen gecikme süresi arttıkça optimal sipariş miktarı anlamlı bir düzeyde azalmaktadır. Stoksuzluk oranı arttıkça optimal sipariş miktarı ödemelerde izin verilen gecikme süresinin düşük olduğu 
değerlerde önce azalmakta belli bir stoksuzluk oranı değerinden sonra ise artmaktadır. Derecesi düşük olan bu azalış ve artışların seyri ödemelerde izin verilen gecikme süresinin 50 günden fazla olduğu durumlarda ortadan kalkmakta ve stoksuzluk oranı arttıkça optimal sipariş miktarı da artmaktadır. Bu iki sonuç beraber ele alındığında en düşük optimal sipariş miktarı en düşük stoksuzluk oranı ile ödemelerde izin verilen gecikme süresinin en yüksek olduğu durumda gerçekleşmektedir.

\section{B. Toplam Kârdaki Değişimlerle İlgili Değerlendirmeler}

Stoksuzluk oranı arttıkça ve defolu ürün oranı azaldıkça toplam kâr artmaktadır. Toplam kârın defolu ürün oranının beklenen değerine karşı daha duyarlı olduğu, stoksuzluk oranındaki değişmeler karşısında ise anlamlı bir düzeyde değişmediği görülmektedir.

Ödemelerde izin verilen gecikme süresi arttıç̧a birim zamandaki toplam kârın optimal beklenen değeri fark edilir miktarda artmaktadır. Stoksuzluk oranındaki değişmeler karşısında toplam kâr; ödemelerde izin verilen gecikme süresinin ilk 30 gününde stoksuzluk oranının belli bir değerine kadar azalmakta fakat ödemelerde izin verilen gecikme süresinin 30 günden fazla olduğu durumlarda stoksuzluk oranı arttıkça toplam kâr da artmaktadır. Yapılan analizler sonucunda birim zamandaki toplam kârın stoksuzluk oranındaki değişimden çok fazla etkilenmediği, ödemelerde izin verilen gecikme süresine göre ise daha fazla duyarlı olduğu sonucuna ulaşılmıştır.

Defolu ürün oranı arttıkça ve ödemlerde izin verilen gecikme süresi azaldıkça toplam kârın optimal değeri azalmaktadır. Toplam kârın ödemelerde izin verilen gecikme süresinden ziyade defolu ürün oranının beklenen değerine karş1 daha duyarlı olduğu görülmektedir. Bunun sonucu olarak toplam kârda anlamlı bir artış sağlamak için defolu ürün oranının düşürülmesi ödemlerde izin verilen gecikme süresinin artmasından daha önemli ve önceliklidir.

\section{SONUÇ}

$\mathrm{Bu}$ çalışmada, ödemelerde gecikmeye izin verilmesi, çevrim süresi içinde karşılanamayan talebin kısmen veya tamamen sonradan karşılanması için stoksuzluğa izin verilmesi ve defolu ürün durumunu ele alan yeni bir model önerilmiştir. Önerilen model için sayısal örnekler verilmiş ve model parametrelerdeki değişimlerin optimal değerleri ne yönde etkilediği duyarlılık analizi ile araştırılmıştır.

Yapılan duyarlılık analizi sonuçlarından talebin erteleme oranının optimal sipariş miktarı ve toplam kâr üzerinde anlamlı bir etkisinin olmadığı görülmüştür. Diğer taraftan ödemelerde izin verilen gecikme süresi arttıkça ve defolu ürün oranı azaldıkça optimal sipariş miktarının azaldığı toplam kârın ise arttığ1 sonucuna ulaşılmıştır. Bulunan sonuçlar daha önce yapılmış çalışmalarla karşılaştırıldığında benzer sonuçlar elde edildiği görülmüştür. Bu çalışma kısmi erteleme, ödemelerde gecikme ve defolu ürün durumunu tek bir modelde ele alması yönüyle önceki çalışmalardan farklılaşmaktadır.

Çalışmada önerilen model; model karmaşıklı̆̆ının artması ve matematiksel çözümün olmaması gibi nedenlerle klasik modellerdeki pek çok katı 
varsayımı da kabul etmektedir. Örnek olarak, stoktaki ürünlerde bozulmanın olmadığ1, talebin sabit ve biliniyor olduğu, paranın zaman değeri ve enflasyon etkisinin dikkate alınmadığı varsayımları önerilen modelde halen geçerlidir. Bu varsayımların gevșetilmesiyle ürünlerde bozulma, farklı talep fonksiyonları ve enflasyon etkisi gibi durumları ele alacak çalışmalar gelecekte yapılabilecektir. Matematiksel çözümün bulunamaması durumunda ise sezgisel yöntemlerin kullanılacağı yeni modeller de geliştirilebilecektir. $\mathrm{Bu}$ tür modellerin geliştirilmesinde bu çalışmada önerilen model kullanılabilecektir.

\section{KAYNAKÇA}

Abad, P. L. (2001). Optimal price and order size for a reseller under partial backordering. Computers \& Operations Research, 28(1), 53-65. doi: Doi 10.1016/S03050548(99)00086-6

Abad, P. L. (2003). Optimal price and lot size when the supplier offers a temporary price reduction over an interval. Computers \& Operations Research, 30(1), 63-74.

Abad, P. L. (2008). Optimal price and order size under partial backordering incorporating shortage, backorder and lost sale costs. International Journal of Production Economics, 114(1), 179-186. doi: 10.1016/j.ijpe.2008.01.004

Aggarwal, S., \& Jaggi, C. (1995). Ordering policies of deteriorating items under permissible delay in payments. Journal of the Operational Research Society, 46(5), 658-662.

Cárdenas-Barrón, L. E. (2000). Observation on:" Economic production quantity model for items with imperfect quality"[Int. J. Production Economics 64 (2000) 59-64]. International Journal of Production Economics, 67(2), 201-201.

Chung, K.-J. (1998). A theorem on the determination of economic order quantity under conditions of permissible delay in payments. Computers \& Operations Research, 25(1), 49-52.

Chung, K.-J., \& Huang, Y.-F. (2006). Retailer's optimal cycle times in the EOQ model with imperfect quality and a permissible credit period. Quality and Quantity, 40(1), 59-77.

Dye, C.-Y., \& Ouyang, L.-Y. (2005). An EOQ model for perishable items under stock-dependent selling rate and time-dependent partial backlogging. European Journal of Operational Research, 163(3), 776-783.

Eroglu, A., \& Ozdemir, G. (2007). An economic order quantity model with defective items and shortages. International Journal of Production Economics, 106(2), 544-549.

Eroğlu, A., vd. (2004). Kusurlu Ürünler İçin Bir Ekonomik Üretim Miktari Modeli. Süleyman Demirel Üniversitesi İktisadi ve İdari Bilimler Fakültesi Dergisi, 9(2).

Giri, B., vd. (2005). An economic production lot size model with increasing demand, shortages and partial backlogging. International Transactions in Operational Research, 12(2), 235-245.

Goyal, S. K. (1985). Economic order quantity under conditions of permissible delay in payments. Journal of the Operational Research Society, 36(4), 335-338.

Goyal, S. K., \& Cárdenas-Barrón, L. E. (2002). Note on: economic production quantity model for items with imperfect quality-a practical approach. International Journal of Production Economics, 77(1), 85-87.

Hadley, G., \& Whitin, T. M. (1963). Analysis of inventory systems. Prentice-Hall, Englewood Cliffs, N.J.

Hwang, H., \& Shinn, S. W. (1997). Retailer's pricing and lot sizing policy for exponentially deteriorating products under the condition of permissible delay in payments. Computers \& Operations Research, 24(6), 539-547.

Jaber, M. Y., vd. (2014). Economic order quantity models for imperfect items with buy and repair options. International Journal of Production Economics, 155, 126-131.

Jamal, A., vd. (1997). An ordering policy for deteriorating items with allowable shortage and permissible delay in payment. Journal of the Operational Research Society, 48(8), 826833. 
Jamal, A., vd. (2000). Optimal payment time for a retailer under permitted delay of payment by the wholesaler. International Journal of Production Economics, 66(1), 59-66.

Khalilpourazari, S., vd. (2016). Optimization of multi-product economic production quantity model with partial backordering and physical constraints: SQP, SFS, SA, and WCA. Applied Soft Computing, 49, 770-791.

Maddah, B., \& Jaber, M. Y. (2008). Economic order quantity for items with imperfect quality: revisited. International Journal of Production Economics, 112(2), 808-815.

Montgomery, D. C., vd. (1973). Inventory models with a mixture of backorders and lost sales. Naval Research Logistics Quarterly, 20(2), 255-263.

Omar, M., vd. (2010). An alternative approach to analyze economic ordering quantity and economic production quantity inventory problems using the completing the square method. Computers \& Industrial Engineering, 59(2), 362-364.

Padmanabhan, G., \& Vrat, P. (1995). Theory and Methodology: EOQ models for perishable items under stock dependent selling rate. European Journal of Operational Research, 86, 281292.

Papachristos, S., \& Konstantaras, I. (2006). Economic ordering quantity models for items with imperfect quality. International Journal of Production Economics, 100(1), 148-154.

Papachristos, S., \& Skouri, K. (2000). An optimal replenishment policy for deteriorating items with time-varying demand and partial-exponential type-backlogging. Operations Research Letters, 27(4), 175-184.

Papachristos, S., \& Skouri, K. (2003). An inventory model with deteriorating items, quantity discount, pricing and time-dependent partial backlogging. International Journal of Production Economics, 83(3), 247-256.

Park, K. S. (1982). Inventory model with partial backorders. International journal of systems Science, 13(12), 1313-1317.

Pentico, D. W., \& Drake, M. J. (2009). The deterministic EOQ with partial backordering: a new approach. European Journal of Operational Research, 194(1), 102-113.

Pentico, D. W., vd. (2009). The deterministic EPQ with partial backordering: a new approach. Omega, 37(3), 624-636.

Rosenberg, D. (1979). A new analysis of a lot-size model with partial backlogging. Naval Research Logistics Quarterly, 26(2), 349-353.

Rosenblatt, M. J., \& Lee, H. L. (1986). Economic production cycles with imperfect production processes. IIE transactions, 18(1), 48-55.

Roy, M. D., vd. (2011). An economic order quantity model of imperfect quality items with partial backlogging. International journal of systems Science, 42(8), 1409-1419.

Salameh, M., \& Jaber, M. (2000). Economic production quantity model for items with imperfect quality. International Journal of Production Economics, 64(1-3), 59-64.

San-José, L.-A., vd. (2008). A backorders-lost sales EOQ inventory model with quadratic shortage cost. Paper presented at the Proceedings of the Pyrenees international workshop on statistics, probability and operations research, Jaca, Spain.

San-José, L., vd. (2007). An economic lot-size model with partial backlogging hinging on waiting time and shortage period. Applied Mathematical Modelling, 31(10), 2149-2159.

San-José, L. A., vd. (2009). A general model for EOQ inventory systems with partial backlogging and linear shortage costs. International journal of systems Science, 40(1), 59-71.

Sana, S. S. (2010). Optimal selling price and lotsize with time varying deterioration and partial backlogging. Applied Mathematics and Computation, 217(1), 185-194.

Sarkar, B., \& Saren, S. (2016). Product inspection policy for an imperfect production system with inspection errors and warranty cost. European Journal of Operational Research, 248(1), 263-271.

Sarkar, B., \& Sarkar, S. (2013). An improved inventory model with partial backlogging, time varying deterioration and stock-dependent demand. Economic Modelling, 30, 924-932.

Sharifi, E., vd. (2015). An EOQ model for imperfect quality items with partial backordering under screening errors. Cogent Engineering, 2(1), 994258. 
Sphicas, G. P. (2006). EOQ and EPQ with linear and fixed backorder costs: Two cases identified and models analyzed without calculus. International Journal of Production Economics, $100(1), 59-64$.

Sulak, H. (2008). Stok kontrolü ve ekonomik sipariş miktar modellerinde yeni açılımlar: ödemelerde gecikmeye izin verilmesi durumu ve bir model önerisi. Sosyal Bilimler.

Sulak, H., \& Eroğlu, A. (2009). Ödemelerde Gecikmeye İzin Verilmesi Durumu Altında Ekonomik Sipariş ve Üretim Miktarı Modelleri Literatür Taraması. Süleyman Demirel Üniversitesi İktisadi ve İdari Bilimler Fakültesi Dergisi, 14(1).

Taleizadeh, A. A., vd. (2016). An EOQ inventory model with partial backordering and reparation of imperfect products. International Journal of Production Economics, 182, 418-434.

Taleizadeh, A. A., vd. (2012). An economic order quantity model with partial backordering and a special sale price. European Journal of Operational Research, 221(3), 571-583.

Taleizadeh, A. A., vd. (2013). An EOQ model with partial delayed payment and partial backordering. Omega, 41(2), 354-368.

Wee, H.-M. (1993). Economic production lot size model for deteriorating items with partial backordering. Computers \& Industrial Engineering, 24(3), 449-458.

Wee, H.-M. (1999). Deteriorating inventory model with quantity discount, pricing and partial backordering. International Journal of Production Economics, 59(1-3), 511-518.

Wee, H.-M., vd. (2014). An EPQ model with partial backorders considering two backordering costs. Applied Mathematics and Computation, 232, 898-907.

Wee, H. M. (1989). Optimal inventory policy with partial backordering. Optimal Control Applications and Methods, 10(2), 181-187.

Wee, H. M., vd. (2007). Optimal inventory model for items with imperfect quality and shortage backordering. Omega, 35(1), 7-11.

Yang, H.-L., vd. (2010). An inventory model under inflation for deteriorating items with stockdependent consumption rate and partial backlogging shortages. International Journal of Production Economics, 123(1), 8-19.

Zeng, A. Z. (2001). A partial backordering approach to inventory control. Production Planning \& Control, 12(7), 660-668.

\section{SUMMARY}

The most widely used stock control models are the deterministic classic economic order and production quantity models. Although these models are simple and useful, they are insufficient to respond to the problems that arise in real life. Therefore, new models are developed by adding additional assumptions to the assumptions in these models or by loosening existing assumptions. Some of the basic assumptions contained in these models are that the incoming order does not contain defective products, shortages and delay in payments are not allowed. Many new models have been developed to address the situation in which permissible delay in payments, defective items and allowable shortages by loosening these assumptions.

The shortage case has two end results, namely "lost sales" and the "complete backordering". The "lost sales" is due to the lack of non-fulfillment of the demands of some customers due to the lack of inventory. "Complete backordering" means the situation where customers are willing to wait until the next period for their unresponsive demands if no inventory is available. There is an infinite number of "partial backordering" situations in which a part of the demand is postponed until the next order arrives.

This study proposes a new economic order quantity model, which allows delay in payments, defective product and partial backordering of unmet demand. 
In the proposed model, the aim is to find the maximum amount of backordering with the optimal order quantity to make the maximum of the total revenue. For this purpose; total cost, total income and total profit functions in unit time were obtained according to two different conditions of the delay period. Using these functions, the optimal order quantity and the maximum allowable amount of backordering amount are obtained for both cases. Special cases of the model were also examined and some of the previously developed models were shown to be the special case of the model proposed in this study. The validity and results of the model were evaluated with numerical examples. Results about optimal order quantity and total profit are summarized as follows:

The optimal order quantity increases as the permissible delay in payments decreases and the expected value of the defective product rate increases. On the other hand, the optimal order quantity first decreases and then increases as backordering rate increases and increases as defective item rate increases. When the two results are considered together, the lowest optimal order quantity is reached by the lowest value of defective product rate and a certain backordering rate. Similarly, the optimal order quantity decreases significantly as permissible delay in payments increases.

Total profit increases as the backordering rate increases and the defective item rate decreases. It is seen that the total profit is more sensitive to the expected value of the defective item rate and it has not changed significantly in the face of the changes in the rate of shortages and backordering. As permissible delay time in payments increases, the optimal expected value of the total profit in the unit time increases noticeably. In the first 30 days of the permissible delay in payments, total profit decreases to a certain value of backordering rate, but in cases where the permissible delay time is more than 30 days, total profit increases as the backordering rate increases.

The results obtained with the model analysis developed in this study are consistent with the previous study results. The model obtained differs from those studies by modeling and analyzing the different situations discussed in previous studies such as permissible delay in payments, defective item and partially backordering of the demand.

Most of the assumptions in classical models are accepted in this study. For example, the fact that many products in stock could deteriorate over time, the existence of different demand functions, the time value of money and the effect of inflation and the continuous supply situation have been neglected in this study. This study will be developed through future studies, where new models will be obtained, including multiple product status, time deterioration of products, time value of money and inflation, different demand functions, continuous supply and deferment rate in different functional structure. With this aspect, it is expected that this study will be the basis for the studies to be carried out. 